\section{Getting into medical school - a guide for dental graduates}

\author{
T. Pepper ${ }^{1}$ and S. Tabiat-Pour ${ }^{2}$
}

IN BRIEF
Provides information on applying to
medical school which is specific to the
dental graduate.
- Outlines the admissions process.
Provides an overview of the medical
degrees available in the UK and discusses
the various admissions tests and
interview types.
Provides information on the amount of
financial support dental graduates are
likely to receive.

Dentists may apply to medical school with a view to ultimately specialising in oral and maxillofacial surgery or oral medicine. While there is much information on applying to medical school, very little is specific to the dental graduate. This paper discusses the contemporary admissions process including the application form, admissions tests, and interview.

\section{INTRODUCTION}

The buzz of Fresher's week, cheap beer, late nights, plentiful sport, regular lieins... What could be better than returning to university as an older, wiser student and reliving your younger days? If you're a dentist considering a medical degree, however, it's likely that you're aspiring to a career in either oral and maxillofacial surgery (OMFS) or oral medicine, and as such, your priorities second-time round are likely to be somewhat different. While many books have been written on applying to medical school, none address the unique position of the dental graduate. It is my intention to disseminate some of the information that is relevant to this small but important group - information that I would have been grateful to have had all in one place as I went through the application process last year.

The admissions procedure has changed markedly in the last decade. Paper forms have been replaced by online application, admission tests are now rife, and contemporary interview techniques are being employed. In a similar vein, many courses have been redeveloped and now have a greater emphasis on problem-based

1*Dental Officer, Dental Centre, 40 Commando Royal Marines, Norton Manor Camp, Taunton, TA2 6PF; 2Restorative Specialist Registrar, Guy's and St Thomas' NHS Foundation Trust

${ }^{*}$ Correspondence to: Surg Lt Cdr (D) Tom Pepper Email:oc.teeth@googlemail.com

\section{Refereed Paper}

Accepted 24 November 2009

DOI: $10.1038 /$ sj.bdj.2010.104

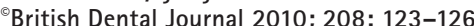

learning (PBL) and computer-assisted teaching. Hands-on experience of cadaverbased dissection is in decline, ${ }^{1}$ with an increasing emphasis on learning from pre-dissected specimens (prosection). Examination styles are continuing to move away from essay-based questions towards computer-marked multiple choice questions, short answer questions, and 'best of five' questions. In short, much of what became familiar during your time as a dental student will now be outmoded.

\section{WHICH MEDICAL SCHOOL?}

Factors influencing choice of medical school for undergraduate applicants include reputation, type of course, geographic location, current student opinions, and social life. ${ }^{2,3}$ Although there are no data for dental graduates, this group is likely to view the following as important: 1) length of course; 2) geographic location; and 3) type of course.

The medical degrees currently available to dental graduates range from three to six years in duration. Schools vary greatly in the importance they place on a dental degree. In England, universities that have both medical and dental schools tend to have shorter medical courses available to dental graduates. University dental hospitals offer the benefits of a nearby source of work which is necessary to maintain skills, gain experience, and fund studies. Information on a school-by-school basis is provided in Table 1 .

Intakes - particularly of dental graduates - vary year on year, and some of the shortest courses do not have places for applicants without home/EU status. In some universities there are separate routes to the same course. For instance, King's College London offers two four-year MBBS courses - a graduate entry programme and a 'maxfax entry' programme. These have different entrance requirements (UKCAT and MJDF, respectively) and are interviewed for separately, but ultimately lead to the same course. Warwick University runs an exclusively graduate course, meaning that the usual second year integration of undergraduate and graduate entry programmes does not occur. Still other courses may be split between universities depending on the year of study (eg Durham and Newcastle, St Andrews and Manchester, Oxbridge and London).

Teaching methods throughout medical courses can be classified as systemsbased (traditional), PBL, or mixed, and it is important to know which style each of your choices use. Each method has its strengths and weaknesses: while traditional teaching provides information in a systematic and comprehensive lecturedriven format, dental graduates may enjoy the 'real-life' clinical scenarios that characterise PBL courses. While PBL has its critics, ${ }^{4}$ dental graduates are better placed than most to overcome many of the perceived shortcomings.

\section{ADMISSIONS TESTS}

Admissions tests arose out of the need to differentiate candidates who appear equally well qualified and suited to medicine. Although some question their 
validity, one of the three types currently in use is required by virtually all medical schools. Aside from visiting the medical schools you are interested in, registering for an admissions test should be the one of the first things you achieve.

\section{GAMSAT}

The Graduate Medical School Admissions Test (GAMSAT) was developed in Australia and brought into use in the UK in 1999. The test takes a full day to complete and is divided into three sections:

1. Humanities and social sciences (100 mins)

2. Written communication (60 mins)

3. Physical science (170 mins).

The written communication section usually requires two essays debating ethics. The physical science section is not negatively marked so answering all questions is essential. As always with this type of test, starting with the easier questions and progressing to the more difficult is a sound strategy. A score of 0-100 is calculated for each section and the candidate given an overall score which is a weighted average of the three sections (section 3 carries double weighting). Registration closes in mid-August and the test is sat in mid-September. GAMSAT is valid for two consecutive years and can be taken in Bristol, Swansea, London, Nottingham, and Sheffield; it costs £192.

Note that medical schools tend to place a great importance on the GAMSAT score you achieve. Some (such as St George's) decide on candidates for interview based purely on the GAMSAT score.

\section{BMAT}

The BioMedical Admissions Test (BMAT) was introduced in 2003 for students applying to medicine at Oxford, Cambridge, or UCL. In 2005, Imperial also adopted it, but only for their undergraduate course. The test is two hours long and conducted using pen and paper; calculators are not permitted. There are three sections:

1. Aptitude and skills - Multiple choice questions testing critical thinking, logic, and reasoning (60 mins)

2. Scientific knowledge and applications - Multiple choice questions (30 mins)

3. Writing task - Answer one question from three, essay style (30 mins).

Table 1 Medical schools of the United Kingdom. UG = undergraduate; PG = postgraduate. Information accurate as of July 2009

\begin{tabular}{|l|l|l|l|l|}
\hline Medical school & $\begin{array}{l}\text { Shortest medical } \\
\text { degree (yrs) }\end{array}$ & $\begin{array}{l}\text { Places UG } \\
(\mathrm{PG})\end{array}$ & Entrance exam & $\begin{array}{l}\text { Dental } \\
\text { school }\end{array}$ \\
\hline \multicolumn{3}{|c|}{ England }
\end{tabular}

\begin{tabular}{|c|c|c|c|c|}
\hline Barts \& The London & 3 & (5) & MJDF & $\checkmark$ \\
\hline Birmingham & 3 & (5) & MJDF & $\checkmark$ \\
\hline Brighton and Sussex & 5 & $138(27)$ & UKCAT & \\
\hline Bristol & 4 & (19) & MJDF & $\checkmark$ \\
\hline Cambridge & 4 & (22) & BMAT & \\
\hline Durham & 5 & 102 & UKCAT & \\
\hline East Anglia & 5 & 143 & UKCAT & \\
\hline Hull York & 4 & (Variable) & UKCAT+MJDF & \\
\hline Imperial College London & 4 & (50) & UKCAT & \\
\hline Keele & 4 & (10) & GAMSAT & \\
\hline King's College London & 4 & $(24) /(4)$ & UKCAT/MJDF & $\checkmark$ \\
\hline Leeds & 3 & (3) & UKCAT & $\checkmark$ \\
\hline Leicester & 4 & (64) & UKCAT & \\
\hline Liverpool & 4 & (32) & None & $\checkmark$ \\
\hline Manchester & 3 & (2) & UKCAT & $\checkmark$ \\
\hline Newcastle & 4 & (25) & UKCAT & $\checkmark$ \\
\hline Nottingham & 4 & (98) & GAMSAT & \\
\hline Oxford & 4 & 30 & UKCAT & \\
\hline Peninsula College & 5 & $215(21)$ & GAMSAT & $\checkmark$ \\
\hline Sheffield & 5 & 241 & UKCAT & $\checkmark$ \\
\hline Southampton & 4 & (40) & None & \\
\hline St George's & 4 & (112) & GAMSAT & \\
\hline University College London & 5 & 330 & BMAT & \\
\hline Warwick & 4 & (178) & UKCAT & \\
\hline \multicolumn{5}{|c|}{ Scotland } \\
\hline Aberdeen & 5 & $170(27)$ & UKCAT & $\checkmark$ \\
\hline St Andrews & 5 & $180(8)$ & UKCAT & \\
\hline Dundee & 5 & 154 & UKCAT & $\checkmark$ \\
\hline Edinburgh & 5 & 202 & UKCAT & \\
\hline Glasgow & 3 & (Variable) & UKCAT+MJDF & $\checkmark$ \\
\hline \multicolumn{5}{|c|}{ Wales } \\
\hline Cardiff & 4 & (Variable) & UKCAT+MJDF & $\checkmark$ \\
\hline Swansea & 4 & (70) & GAMSAT & \\
\hline \multicolumn{5}{|c|}{ Northern Ireland } \\
\hline Queen's University Belfast & 5 & 262 & UKCAT & $\checkmark$ \\
\hline
\end{tabular}

Section 2 relies heavily on A-level standard knowledge of physics, chemistry, biology, and maths - a distant memory for dental graduates, so thorough preparation is required. The first two sections are marked from 1-9; the third section is marked from 0-15. A typical BMAT candidate will score 5/5/9. Universities differ in how they use 
the results - UCL automatically interview all who score a total over 19; Oxford looks at BMAT score in conjunction with other factors when deciding who to interview.

The BMAT is designed to produce a full range of marks from candidates and, as such, is difficult - particularly in the time permitted. If you are stronger in one subject than another (eg biology) it is worth going through the paper and answering questions relating to this before tackling the others. Bear in mind that, if you are invited to interview, the contents of your essay may form some of the discussion topics. Consequently, it is prudent to make some notes on what you have written after you leave the exam (although some universities will give you a photocopy of your essay before the interview).

The test costs $£ 32.10$ and is generally sat at secondary schools or colleges - as a graduate you will have to contact one of these venues and register to take the test. The deadline for registration is 30 September; the test is generally sat in early November with results being published in early December. BMAT is valid for one year.

\section{UKCAT}

Introduced in 2006, the United Kingdom Clinical Aptitude Test (UKCAT) is the newest of the admissions tests. In fact, the results gained from it are still being validated. Rather than testing academic knowledge, it is designed to test aptitude and attitude. It consists of five sections of multiple choice questions which are shown and answered on a computer screen:

1. Verbal reasoning (21 mins)

2. Quantitative reasoning (21 mins)

3. Abstract reasoning (15 mins)

4. Decision analysis (29 mins)

5. Non-cognitive analysis

(no time limit).

Although the test measures innate skills and therefore supposedly cannot be revised for, it is worth investing in a book of test questions in order to familiarise yourself with the question types. There is considerable time pressure so it is important not to spend too long on one question. The test is not negatively marked so, as always, make sure you answer every question. Each section is scored between 300 and 900 except non-cognitive analysis which is not currently scored. The typical candidate will score 600; you receive your score immediately after the test.

There is currently great variation in how medical schools interpret and use the UKCAT scores. Some universities look at the scores individually; others take an average of all the scores. While some schools use UKCAT score as the sole criterion in an initial sift of candidates (eg Imperial), others take the test scores in conjunction with academic achievements (eg St Andrews). Still others place very little importance on the UKCAT and take the view that while high scores may be an advantage, low scores aren't necessarily a disadvantage if outweighed by other factors in the application. Schools such as East Anglia, Dundee and Sheffield are being conservative in their use of UKCAT results until data are available on the strength of correlation between performance in the UKCAT and performance in medical exams. Most medical schools will indicate on their websites how they intend to use results from the UKCAT.

It is worth noting that some of the universities not requiring an admissions test from graduate applicants nonetheless expect dentally-qualified applicants to have passed some or all of MFDS/MJDF. In addition, usually universities offering direct entry to the clinical years of medicine (ie three year courses) expect dentists to have a minimum of 12 months' experience in an approved hospital post.

\section{UCAS}

Since 2005 the Universities \&t Colleges Admissions Service (UCAS) has been administered exclusively online at www. ucas.ac.uk. UCAS offers a step-by-step process through which to complete your application at a cost of $£ 17$; for the vast majority of medical courses, application through this service is mandatory with a deadline of 15 October in the calendar year before the course commences. (An exception to this is the course for dental graduates at Barts and The London for which application is direct to the School by 15 February in the same calendar year as the course starts.) Applicants using UCAS may list up to four course choices which remain confidential during the process so that universities considering an application cannot see the candidate's other choices. Offers or rejections from all choices are usually made by the end of March.

Most schools assess applications using criteria centred around academic achievements, non-academic achievements, medical experience, the admissions test (as discussed above), and your reference.

The personal statement is limited in length to 4,000 characters (including spaces) or 47 lines, whichever comes first. Leaving yourself enough time to construct a high quality personal statement is essential and, fortunately, a plethora of books and websites are available to assist. An important point for dental graduates is to emphasise experiences and skills gained during time spent as an SHO.

As a dental graduate the most appropriate person to write your reference is a consultant under which you have worked. As he or she may not be aware of the full scope of your past achievements it is prudent to supply them with plenty of time and an up-to-date CV from which they can compile their glowing testimony.

\section{THE INTERVIEW}

Traditionally, the medical school interview has been a 15-30 minute affair with the applicant confronted by a panel of clinicians, academics, and sometimes current students. Although this method has stood the test of time, the tone of the whole interview can easily be set by the applicant's responses to the initial question(s). If the applicant feels they have answered these well, they will grow in confidence and most likely will perform in a similar way for the remainder of the interview. However, the converse is also true. In order to mitigate this, a new format of interview - the multiple mini interview (MMI) - was developed in the USA and has been adopted by a selection of UK universities (eg KCL, East Anglia, Dundee, Belfast). The MMI is delivered in the style of an OSCE (objective structured clinical examination), although it is neither objective nor clinical. Candidates are interviewed for a predetermined time (usually 5-8 minutes) by a single interviewer before moving on to the next station and starting the process again.

The proposed benefits of the MMI are allowing multiple samples of insight into a candidate's abilities and reducing the effects of chance and examiner/situational 
bias. ${ }^{5}$ For instance, if the candidate has a disastrous first station he or she can start with a clean slate on the next station with a new, independent interviewer. However, an effect of this is if the candidate is performing well on a station their momentum is somewhat broken by the change of location and interviewer. Additionally, most MMIs are delivered in a single room divided by screens and the level of noise in the room while questions are being answered can be distracting for some candidates. Although the process takes longer (50-60 minutes) than the traditional format from the candidate's perspective, it does appear to be fairer and indeed a valid predictor of future performance in medical school. ${ }^{6,7}$

Regardless of the interview style used, many interviews currently include one or more ethical scenarios for the candidate to consider and debate. Practice in these will make constructing a high quality response much easier, and fortunately several good resources are available for this purpose. ${ }^{8,9}$ It is important to realise that the interviewer is not looking for your opinion immediately. A discussion considering both sides of the argument is required before concluding with your personal view on how the scenario in question should be resolved.

Interviews should be prepared for in a similar fashion to an exam, but note that rehearsing answers to specific questions is undesirable. Ensure that you know your personal statement and be aware that the interviewers probably won't have read it, or the rest of your UCAS form. Don't wait for the invitation to interview to begin your preparation - there will be a lot of common ground between interviews and they can sometimes arise at short notice (eg one week). Note that while sending your interviewers a CV before the date might have been a sound approach previously, most universities will now not reveal who will sit on your interview panel. Even so,

\section{Table 2 Application checklist}

Application checklist

1. Contact and/or visit medical schools of interest

2. Register with UCAS

3. Book relevant admission tests(s)

4. Request reference

5. Write personal statement

6. Sit admissions test(s)

7. Submit UCAS application

8. Prepare for interview(s)

it is worth contacting your choices to find out their specific policy.

\section{MONEY MATTERS}

Financial considerations are probably the single largest factor preventing dental graduates applying to medical school. Currently, all medical schools in England, Northern Ireland, and (for non-Welsh students) Wales charge the full home tuition fee of $£ 3,225$, while schools in Scotland charge non-Scottish students $£ 2,895$. Those undertaking medicine as a second degree are not currently eligible for a tuition fee student loan. Graduates are, however, eligible for a maintenance loan of $£ 3,564-4,950$ to cover living expenses, $28 \%$ of which is means-tested using household income.

Students on accelerated courses in England and Wales will have their fees paid by the Department of Health and receive a means-tested NHS bursary after the first year. However, those on standard courses will only receive the same assistance from year five.

While information on additional support can be nebulous, NHS hardship grants, Access to Learning funds and, for those with children, child benefits and tax credits are available. Some charitable trusts specifically cater for those studying medicine as a second degree - for instance the Sir Richard Stapley educational trust, the BMA medical education trust, and the Thomas Wall trust. Money4medstudents.org is a website set up by the BMA, Medical Schools Council, National Association of Student Money Advisers, and the Royal Medical Benevolent Fund, which gives a useful overview of possible sources of funding.

\section{CONCLUSION}

The decision to undertake a medical degree as a dentist is the first step on an admissions pathway that will be markedly different to that experienced during application to dental school. Although protracted, the process has arguably evolved into a fairer, more evidence-based procedure than in previous years. If you have made this decision, I sincerely hope that the information provided herein eases the application process and wish you the best of luck in your endeavours. A suggested application checklist is shown in Table 2.

Many thanks to the admissions tutors who provided me with information on their respective courses and admissions procedures.

1. Older J. Anatomy: a must for teaching the next generation. Surg J R Coll Surg Edinb Irel 2004; 2: 79-90.

2. Adams T, Garden A. What influences medical school choice? Med Teach 2006; 28: 83-85.

3. Brown C. A qualitative study of medical school choice in the UK. Med Teach 2007; 29: 27-32.

4. Smithers A. Medical training heading for disaster. The Independent Education Supplement 19 September 2002, page 2.

5. Eva K W, Rosenfeld J, Reiter H I, Norman G R. An admissions OSCE: the multiple mini-interview. Med Educ 2004; 38: 314-326.

6. Eva K W, Reiter H I, Rosenfeld J, Norman G R. The ability of the multiple mini-interview to predict preclerkship performance in medical school. Acad Med 2004; 79: S40-S42.

7. Reiter H I, Eva K W, Rosenfeld J, Norman G R. Multiple mini-interviews predict Clerkship and licensing examination performance. Med Educ 2007; 41: 378-384.

8. Lee G, Picard O. Medical school interviews: a practical guide to help you get that place at medical school - over 150 questions analysed. ISC Medical, 2006.

9. http://www.thestudentroom.co.uk/wiki/Medicine [accessed 11 June 2009]. 